P.F. Spano $\cdot$ M. Memo

\title{
Industrialists set up first school of molecular medicine
}

Recognition of the emerging links between molecular biology and molecular medicine has led to the establishment of the first European School of Molecular Medicine (ESMM). The industrial town of Brescia in northern Italy is developing into one of the international research capitals thanks to an initiative financed by the Camillo Golgi Foundation, an organization set up in 1987 by local businessmen to aid medical research. The courses are open to 60-70 selected experts in the medical field and will take place at the Istituto per la Formazione (ISFOR 2000 ) in Brescia. In addition, other European sites are currently being considered.

Molecular medicine encompasses a wide range of medical disciplines (including oncology, biotechnology, neuroscience, immunology, gene therapy, infectious diseases, cardiovascular medicine) and represents the application of basic knowledge in molecular cell biology directly to clinical medicine. The development of molecular biology has led to a deepening in our understanding of disease, and after a long wait of 20 years it is beginning to produce promising research methods in molecular medicine. This transition is becoming increasingly important, as is the introduction of basic science to the medical field. The flowering of basic biological research, particularly recombinant DNA technology, has opened up new possibilities in clinical medicine. Specialized physicians need to become acquainted with these new technologies, and therefore it is essential that they receive continuing training and education. Without such continuing education, academic medicine and the pharmaceutical industries would become stagnant. In Brescia, senior academics, heads of the University, and representatives from industry have come up with an idea for the future. One of the founders of the ESMM, the present senior author, Prof. Pier Franco Spano, holder of the Chair of Pharmacology at the University of Brescia, has explained that "research invents our future... investment

P.F. Spano ( $\square) \cdot$ M. Memo

Universita Degli Studi di Brescia,

Dipartimento di Scienze Biomediche e Biotecnologie,

Via Valsabbina 19, I-25123 Brescia, Italy in research is the only way to provide a stable cultural and economic future for our country."

The aim of the school is to provide a rapid and efficient information service to bridge the gap between research and the clinic by introducing all those actively involved in the medical field to the medical applications of molecular biology. The first course, which took place 3-5 November 1994 on "Signal transduction in differentiation and trans-differentiation," was greeted with great interest by the medical community and demonstrated how industry can actively assist physicians to meet the challenges of the twenty-first century.

The first Symposium of the ESSM explored molecular and cellular events, triggered by a variety of signals, involved in cell differentiation towards either a normal, or a transformed phenotype. Sessions included: signal transduction and regulation of gene expression, trophic factors and alternative mRNA splicing, and transcription factors in cell differentiation. 